\title{
SERUM FERRITIN AS A PREDICTOR OF EARLY MORTALITY IN CHRONIC LIVER DISEASE AND ITS RELATION TO MELD SCORE
}

\author{
Suresh Moothezhathu Kesavadas ${ }^{1}$, Sreenath Sreenivasan'2, Neethu Suresh ${ }^{3}$, Santhosh Kumar Thulaseedharan Saraswathy ${ }^{4}$ \\ 1 Professor, Department of Internal Medicine, Government Medical College, Trivandrum, Kerala, India. \\ ${ }^{2}$ Additional Professor, Department of Internal Medicine, Government Medical College, Trivandrum, Kerala, India. \\ ${ }^{3}$ Senior Resident, Department of Internal Medicine, Government Medical College, Trivandrum, Kerala, India. \\ ${ }_{4}^{4}$ Associate Professor, Department of Internal Medicine, Government Medical College, Trivandrum, Kerala, India.
}

\section{ABSTRACT}

\section{BACKGROUND}

Orthotopic liver transplantation is the only definitive treatment for end-stage liver disease. Liver transplant waiting list mortality remains a major concern. Hence, it is important to have early predictors of mortality in end-stage liver disease.

Aims and Objectives-

1. To assess the level of serum ferritin in chronic liver disease and its role as a predictor of early mortality.

2. To compare serum ferritin level in patients with chronic liver disease to Modified End-Stage Liver Disease (MELD) score and to measure serum ferritin in various complications of liver disease.

\section{MATERIALS AND METHODS}

This is a prospective observational study. After obtaining Institutional Ethical Committee approval, 250 consenting patients satisfying inclusion criteria were enrolled. Demographic, clinical, biochemical, ultrasonographic and endoscopic parameters were recorded by structured questionnaire. Serum ferritin level was measured (by chemiluminescent method) in each patient. Data analysis was done using SPSS software (Version 15). Tests of significance were done to find the objectives of the study.

\section{RESULTS}

Mean age of the study group was 52.2 years. Male:female ratio was 4.1:1. Serum ferritin was elevated in $41.2 \%$ of patients, decreased in $2 \%$ and normal in $56.8 \%$ of the patients. Increased ferritin level was found to predict early mortality in patients with chronic liver disease, area under curve was 0.682 with $95 \%$ CI ( $0.592-0.772)$. Ferritin level $>500$ has a sensitivity of $53.8 \%$ and specificity of $74.4 \%$ to predict the mortality. Serum ferritin correlates positively with MELD score. Mean ferritin in ascites was 490.16, SBP- 479.52, variceal bleed- 700.88, hepatorenal syndrome- 627.01 and in hepatic encephalopathy- 572.59.

\section{CONCLUSION}

Elevated serum ferritin is an early predictor of mortality in CLD and it is elevated in various complications of chronic liver disease and correlates well with MELD score.

\section{KEY WORDS}

Serum Ferritin, Chronic Liver Disease (CLD), Modified End-Stage Liver Disease (MELD), Non-Alcoholic Steatohepatitis (NASH), Hepatitis B Virus (HBV).

HOW TO CITE THIS ARTICLE: Kesavadas SM, Sreenivasan S, Suresh N, et al. Serum ferritin as a predictor of early mortality in chronic liver disease and its relation to MELD score. J. Evolution Med. Dent. Sci. 2018;7(29):3338-3342, DOI: $10.14260 /$ jemds/2018/752

\section{BACKGROUND}

Liver is the largest vital organ of the body, weighing $1-1.5 \mathrm{~kg}$, which is $1.5-2.5 \%$ of the lean body mass and is about $1 / 50$ of total body weight. ${ }^{1}$ It plays a major role in synthesis of proteins, regulation of nutrients, metabolism and conjugation of bilirubin and drugs, detoxification, production of bile and maintenance of immunity (Kupffer cells).

Chronic Liver Disease (CLD) refers to disease of the liver, which had lasted more than six months. Disease process involves progressive destruction and regeneration of liver

'Financial or Other Competing Interest': None.

Submission 03-02-2018, Peer Review 29-06-2018,

Acceptance 07-07-2018, Published 16-07-2018.

Corresponding Author:

Dr. Sreenath Sreenivasan

Additional Professor,

Department of Internal Medicine,

Government Medical College,

Trivandrum, Kerala, India.

E-mail: sreenaths02@gmail.com

DOI: $10.14260 /$ jemds $/ 2018 / 752$

\section{(c) (i) $($ ) (}

parenchyma leading to fibrosis and cirrhosis. For predicting prognosis of end-stage liver disease, various prognostic models are in use.

An article published by Elizabeth et $\mathrm{al}^{2}$ in Annals of Internal Medicine in 2003 showed correlation between ferritin levels and the degree of hepatic fibrosis. Cirrhosis had a probability of $7.4 \%$ when serum ferritin level was less than $1000 \mathrm{ng} / \mathrm{mL}$; when compared to $72 \%$ among those with ferritin levels more than $1000 \mathrm{ng} / \mathrm{mL}$; when age and elevated liver enzymes were adjusted.

A Jacobs and M Norwood ${ }^{3}$ (in NEJM 1975) showed high ferritin concentrations associated with severe or active hepatocellular disease. Serum ferritin is an independent predictor of histologic severity and advanced fibrosis in patients with Non-Alcoholic Fatty Liver Disease (NAFLD) as studied by Kowdley KV et al. ${ }^{4}$

In recent times, Model for End-Stage Liver Disease (MELD) score has been developed to replace Child-Pugh score. 5 The MELD score is significant in predicting the severity of liver disease and also in predicting mortality in cirrhosis. Number of studies have shown that MELD score 
predicts short-term mortality at 3 months. Hence, it is used to prioritise cadaveric liver transplants.

Some recent studies show that serum ferritin predicts mortality and complications of cirrhosis in patients with decompensated cirrhosis awaiting liver transplantation. ${ }^{6}$ Ferritin levels are significantly raised in acute liver failure.6,7 Ferritin is elevated in hepatic necroinflammation and can be used as a marker of liver disease. Among chronic liver diseases, apart from haemochromatosis, hyperferritenemia is also described in patients with metabolic syndrome, nonalcoholic fatty liver disease and viral related chronic liver diseases. In patients with NAFLD, ${ }^{8}$ studies have shown that in patients without iron accumulation in the liver, elevated ferritin concentration is more reflective of histological damage rather than iron overload. ${ }^{9}$

Ferritin is a 24-subunit evolutionarily conserved protein. Within the cytosol, ferritin stores iron in a non-toxic form which is soluble, thereby it protects cells from iron-mediated cytotoxic oxidation-reduction reactions. Damaged hepatocytes release ferritin into serum. It correlates with the rise in alkaline phosphatase. This signifies the presence of ferritin in cytosol of hepatocytes. Thus, serum ferritin can be used as an indirect marker of hepatic necroinflammation.

Currently, there are not much prognostic markers indicating very early mortality in chronic liver disease. Hence, in this study we attempt to study the role of serum ferritin in predicting the 15-day mortality of patients admitted with cirrhosis and also relation of serum ferritin to MELD score.

\section{Aims and Objectives}

Primary objective is to assess the level of serum ferritin in patients presenting with chronic liver disease and its role as a predictor of early mortality. Secondary objectives are comparing the level of serum ferritin with MELD score and measurement of serum ferritin in various complications of chronic liver disease.

\section{MATERIALS AND METHODS}

This is a prospective observational study, conducted among patients admitted to medical wards of Internal Medicine Department of Medical College Hospital, Trivandrum, done over a period of 1 year from January 2015. Total sample size was 250 and sample size was taken conveniently.

This is based on a study by Rakhi Maiwall et al 10 according to which the serum ferritin predicts early mortality in patients with decompensated cirrhosis, proportion of death in high ferritin group was $41.5 \%$ and that in low ferritin group was $25 \%$.

All patients with liver disease whose symptoms and signs persists for more than 6 months were classified as CLD, are included in the study. Diagnosis was supported by Ultrasonography (USG) of abdomen.

Patients with primary hemophagocytic and lymphohistiocytic syndromes, patients with iron overload, those with hepatocellular carcinoma, those with comorbidities with poor outcome- extrahepatic neoplasia, severe cardiopulmonary disease with NYHA > 3, oxygen dependent or steroid dependent COPD patients and patients who do not give an informed written consent were excluded.
Study was conducted using a structured data collection proforma. After ethical clearance, permissions were obtained from Head of the Department of Internal medicine. History, physical examination, blood investigations, radiographic assessment, ascitic fluid study and upper GI endoscopy were done to establish a diagnosis of CLD and its complications. Those found to have CLD were informed about the study in native language. After satisfying the exclusion criteria and getting informed consent, the structured proforma was filled with respective data with clinical details of patients including history and complications of chronic liver disease like ascites, hepatic encephalopathy, SBP, gastrointestinal bleed and hepatorenal syndrome.

Serum ferritin was measured in all patients using chemiluminescent method. A ferritin value of 23.9 - 336.2 $\mathrm{ng} / \mathrm{mL}$ in males and $11-306.8 \mathrm{ng} / \mathrm{mL}$ in females was the normal levels set. For comparison with previous studies patients were divided as having ferritin levels $<200,200-400$ and $>400 \mathrm{ng} / \mathrm{mL}$. MELD was calculated as $0.957 \times \log$ (creatinine) $+0.378 \times \log ($ total bilirubin $)+1.120 \times \log ($ INR $)+$ 0.6431 .

Creatinine was measured by Jaffe's method and bilirubin by modified method of Pearlman and Lee.11 Normal Prothrombin time was defined as 12.4 seconds and INR, 1. After obtaining the written informed consent, patients underwent upper gastrointestinal endoscopy on overnight fasting. Endoscopy was correlated with other findings to establish the diagnosis.

Data analysis was done using SPSS 15 version. The qualitative data were expressed as numbers and percentage. Descriptive statistics were mentioned as mean and standard deviation. Comparison of categorical variables was done by Chi-square test. Ferritin levels in CLD patients were estimated and its role in predicting mortality was analysed and ferritin levels were compared with MELD score using One-Way ANOVA and independent sample ' $t$ ' test. ROC curve is used to find optimum cut-off value of ferritin for predicting mortality. Association of S. ferritin to mortality was assessed by univariate analysis. All statistical tests were 2 tailed and a significance level (p) of 0.05 was used.

\section{RESULTS}

In this prospective observational study, 250 patients with chronic liver disease who met the inclusion and exclusion criteria were studied. Serum ferritin was measured in all patients.

In this study, 201 patients were males (80.4\%) and 49 $(19.6 \%)$ were females. Majority of patients were between ages 40 - 60 years. Mean age of the study group was 52.2 years. Mean age in ferritin $<200$ group was 53.3, 200-400 was 49.8 and $>400$ was 52.1 .

Most common aetiology of Chronic Liver Disease (CLD) was alcoholism in cirrhotic dose. It was present in $51.6 \%$ patients- $51.7 \%$ of $<200 \mathrm{ng} / \mathrm{mL}$ ferritin group, $57.2 \%$ of 200 400 and $47.1 \%$ of $>400 \mathrm{ng} / \mathrm{mL}$ group had alcoholism. $26 \%$ of patients had NASH- $28.4 \%$ in $<200 \mathrm{ng} / \mathrm{mL}, 16.3 \%$ of $200-400$ and $28.2 \%$ of $>400$ had NASH. $18 \%$ of our patients had hepatitis B. $10.3 \%$ of patients in $<200 \mathrm{ng} / \mathrm{mL}, 18.4 \%$ of 200 400 and $14.4 \%$ of $>400 \mathrm{ng} / \mathrm{mL}$ had hepatitis B. Hepatitis C was reported in $2.7 \%$. 


\begin{tabular}{|c|c|c|}
\hline \multicolumn{3}{|l|}{ Frequency distribution of various etiologies in the sample } \\
\hline Etiology & Frequency & Percent \\
\hline Alcohol & 129 & 51.6 \\
\hline HBV & 36 & 14.4 \\
\hline HCV & 7 & 2.8 \\
\hline NASH & 65 & 26 \\
\hline OccultHBV & 9 & 3.6 \\
\hline Autoimmune & 5 & 2 \\
\hline Cryptogenic & 13 & 5.2 \\
\hline Wilsons & 2 & 0.8 \\
\hline \hline
\end{tabular}

Infections were present in $63.6 \%$ of patients. Pneumonia $(21.2 \%)$, urinary tract infection $(20.8 \%)$, cellulitis $(14.8 \%)$ and SBP (19.6\%) were the common infections reported in our study group. Pneumonia occurred in $19.8 \%$ of $<200,26.5 \%$ of $200-400$ and $21.2 \%$ of $>400$ groups. Cellulitis occurred in $6 \%, 12.2 \%$ and $28.2 \%$ of $<200,200-400$ and $>400$ groups respectively. SBP occurred in $19 \%, 14.3 \%$ and $23.5 \%$ of $<200$, 200-400 and $>400 \mathrm{ng} / \mathrm{mL}$ ferritin groups respectively.

Co-morbidities were present in $51.6 \%$ of population. Diabetes (22\%), hypertension (22\%), dyslipidaemia $(8.4 \%)$ and $\mathrm{CAD}(6.4 \%)$ were the common co-morbidities in this study population.

\begin{tabular}{|c|c|c|}
\hline \multicolumn{3}{|c|}{$\begin{array}{l}\text { Frequency distribution of various } \\
\text { comorbidities in the sample }\end{array}$} \\
\hline Co morbidities & Frequency & Percent \\
\hline Co morbidities & 129 & 51.6 \\
\hline DM & 55 & 22 \\
\hline HTN & 55 & 22 \\
\hline CAD & 16 & 6.4 \\
\hline COPD & 2 & 0.8 \\
\hline CVA & 2 & 0.8 \\
\hline $\mathrm{TB}$ & 3 & 1.2 \\
\hline Seizure & 5 & 2 \\
\hline Dyslipedimia & 21 & 8.4 \\
\hline Thyroid & 6 & 2.4 \\
\hline Psychiatric & 2 & 0.8 \\
\hline CKD & 2 & 0.8 \\
\hline
\end{tabular}

Mean ferritin in the study group was $488.7 \mathrm{ng} / \mathrm{mL}$. Serum ferritin was low in $2 \%$, elevated in $56.8 \%$ and normal in rest of the patients. $46.4 \%$ had ferritin $<200,19.6 \%$ had ferritin $200-400$ and $34 \%$ had ferritin $>400 \mathrm{ng} / \mathrm{mL}$.

Mean MELD score in $<200$ group was 17.75, in $200-400$ was 25.32 and $>400$ group was 31.07. So as ferritin increases, MELD score also increases $(p<0.001)$ and there was significant correlation between MELD score and serum ferritin.

These findings correlate to the study by Walker et al.

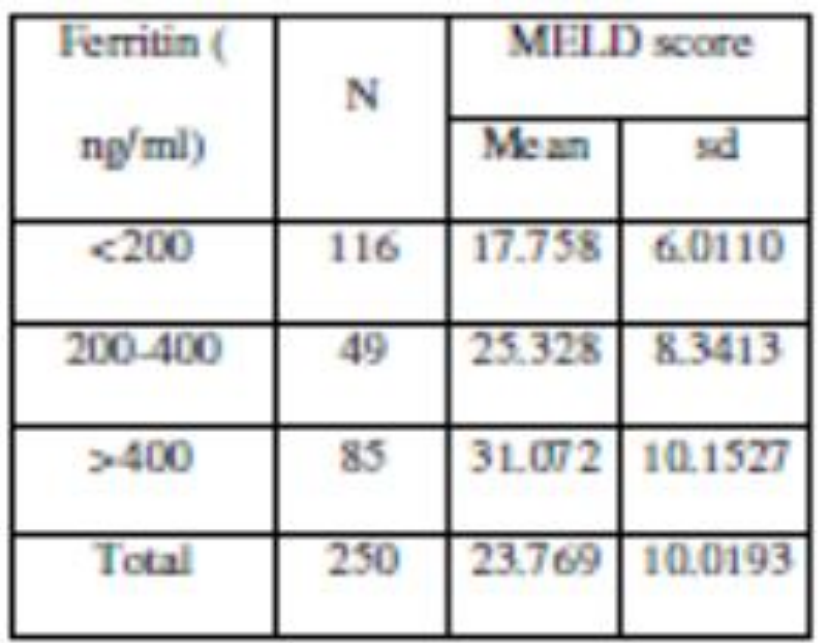

Mean MELD Score in various Ferritin Groups

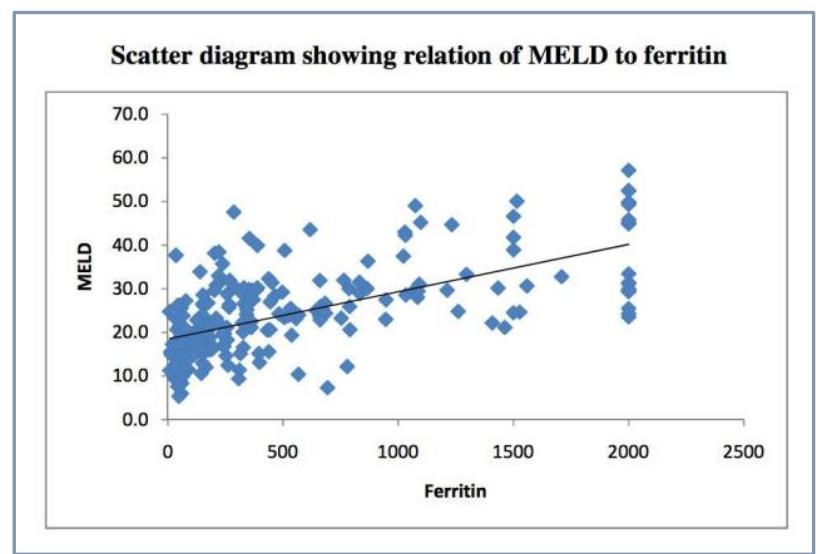

$90 \%$ of patients belonged to Child $\mathrm{C}$ and $10 \%$ belonged to Child B- $16.4 \%$ of $<200,6.1 \%$ of $200-400$ and $3.5 \%$ of $>$ $400 \mathrm{ng} / \mathrm{mL}$ ferritin group belonged to Child B. $83.6 \%$ of $<200$, $93.9 \%$ of $200-400$ and $96.5 \%$ of $>400$ belonged to Child C. As the Child score increases, serum ferritin increases and it was found to be significant ( $\mathrm{p}-0.000$ ).

$15.6 \%$ of patients expired among the study population. $6.9 \%$ of $<200,20.4 \%$ of $200-400$ and $24.7 \%$ of $>400$ group died. As ferritin level increases, mortality increases and change was found to be significant. Mean ferritin in mortality group was 791.5 and that in alive group was 432.5 and the difference was significant. A ferritin value of 500 had a sensitivity of $53.8 \%$ and specificity of $74.4 \%$ with the area under curve of 0.682 with $95 \%$ CI $(0.592-0.772)$. 


\begin{tabular}{|c|c|c|c|c|c|c|c|c|c|}
\hline \multirow{3}{*}{ Mortality } & \multicolumn{6}{|c|}{ Ferritin } & & & \multirow{3}{*}{ P } \\
\hline & \multicolumn{2}{|c|}{$<200$} & \multicolumn{2}{|c|}{$200-400$} & \multicolumn{2}{|c|}{$>400$} & \multicolumn{2}{|c|}{ TOTAL } & \\
\hline & $\mathrm{N}$ & $\%$ & $\mathrm{~N}$ & $\%$ & $\mathrm{~N}$ & $\%$ & $\mathrm{~N}$ & $\%$ & \\
\hline Dead & 8 & 6.9 & 10 & 20.4 & 21 & 24.7 & 39 & 15.6 & 0.002 \\
\hline Alive & 108 & 93.1 & 39 & 79.6 & 64 & 75.3 & 211 & 84.4 & \\
\hline Total & 116 & 100 & 49 & 100 & 85 & 100 & 250 & 100 & \\
\hline
\end{tabular}

Distribution of Mortality in various Ferritin Groups

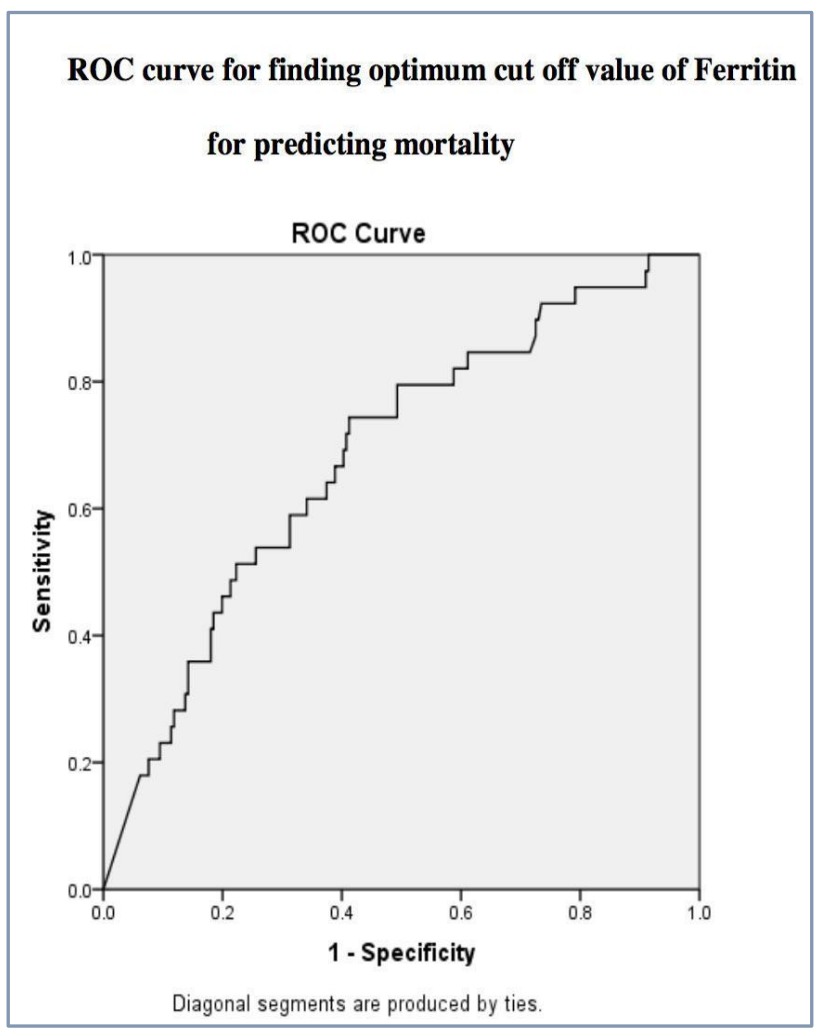

$144(85.6 \%)$ patients had ascites. $81.9 \%$ of $<200,87.8 \%$ of $200-400$ and $89.4 \%$ of $>400 \mathrm{ng} / \mathrm{mL}$ ferritin group had ascites. This difference was not statistically significant. Mean ferritin in ascites group was 490.2 and that in non-ascitic group was 479.9. This is similar to Rakhi Maiwall et al study group, but ascites was not related to ferritin levels. In their study, Walker et al 12 also could not find significant association of ascites to ferritin.

$50(20 \%)$ of patients had Spontaneous Bacterial Peritonitis (SBP). Mean ferritin in those with SBP was 489.9 and those without was 489.1. The difference was not statistically significant. $19.8 \%$ of those in ferritin < 200, $14.3 \%$ of $200-400$ and $23.5 \%$ of $>500$ groups had SBP. The difference was not statistically significant.

Variceal bleed from Upper Gastrointestinal Tract (UGIB) was seen in 101 (40.4\%) of patients. Mean ferritin in those with UGIB was 703.5 and those without was $344 \mathrm{ng} / \mathrm{mL}$. It was statistically significant $(p<0.001)$. So as ferritin increases, occurrence of UGIB increases.

Hepatorenal syndrome occurred in 104 (41.6\%) of patients. Mean ferritin in those with HRS was 588.7 and those without was $407.2 \mathrm{ng} / \mathrm{mL}$. This difference was significant (p-
0.015). $23.3 \%$ of those in ferritin $<200,57.1 \%$ of $200-400$ and $57.7 \%$ of $>400$ groups had HRS (p- 0.00 ).

\begin{tabular}{|c|c|c|c|c|c|c|c|c|c|}
\hline \multirow{2}{*}{} & \multicolumn{5}{|c|}{ Ferritin } & \multicolumn{2}{|c|}{} & \multirow{2}{*}{ TOTAL } & \multirow{2}{*}{ P } \\
\cline { 2 - 7 } & \multicolumn{2}{|c|}{$<200$} & \multicolumn{2}{|c|}{$200-400$} & \multicolumn{2}{|c|}{$>400$} & \multicolumn{2}{|c|}{ TOT } \\
\cline { 2 - 7 } & $\mathrm{N}$ & $\%$ & $\mathrm{~N}$ & $\%$ & $\mathrm{~N}$ & $\%$ & $\mathrm{~N}$ & $\%$ & \\
\hline Ascites & 95 & 81.9 & 43 & 87.8 & 76 & 89.4 & 214 & 85.6 & 0.290 \\
\hline UGIB & 32 & 27.6 & 17 & 34.7 & 52 & 61.2 & 101 & 40.4 & 0.000 \\
\hline HE & 54 & 46.6 & 29 & 59.2 & 61 & 71.8 & 144 & 57.6 & 0.002 \\
\hline SBP & 23 & 19.8 & 7 & 14.3 & 20 & 23.5 & 50 & 20 & 0.435 \\
\hline HRS & 27 & 23.3 & 28 & 57.1 & 49 & 57.6 & 104 & 41.6 & 0.000 \\
\hline
\end{tabular}

Complications of Liver Disease in various Ferritin Groups

Hepatic Encephalopathy (HE) was seen in 144 (57.6\%) of patients. Mean ferritin in those with HE was 572.7 and those without HE was $375.8 \mathrm{ng} / \mathrm{mL}$. This difference was significant (p- 0.009). Mean ferritin in HE Grade 1 was 358.8, Grade 2 was 528.4, Grade 3 was 485.5 and Grade 4 was 599.9 ng/mL. So as ferritin increases, grade of hepatic encephalopathy also increases.

Mean haemoglobin in ferritin $<200$ was 9.4, $200-400$ was 9.5 and $>400$ was 7.5 (p- 0.000). Total leucocyte count in $<200$ group was 8962, $200-400$ was 11045 and $>400$ was 13049 (p- 0.000). Mean creatinine in $<200$ was $1.3,200-400$ was 1.8 and $>400$ was 2.1 (p- 0.001). Mean INR in $<200$ was $1.7,200-400$ was 2.2 and $>400$ was 3.3 .

After analysis, CTP score, haemoglobin, total leucocyte count, MCV, blood urea, serum creatinine and PT/ INR independently had significant association to serum ferritin.

\section{DISCUSSION}

To allocate and prioritise the cadaveric liver to patients with decompensated chronic liver disease, the MELD score has been an excellent model. The MELD score includes many objective variables, while the CTP score consists of two subjective parameters, i.e. ascites and encephalopathy. The performance of these two scores was compared in several studies found conflicting results, but neither of these scores was validated for prediction of early mortality in patients with chronic liver disease like cirrhosis. ${ }^{13}$

Serum ferritin, which is primarily an intracellular protein constituting the major body iron stores is also present in serum in traces. Patients with liver disease have high serum ferritin levels due to hepatic necroinflammation and release of ferritin from damaged hepatocytes or secondary to macrophage activation. ${ }^{14-16}$ Walker et al demonstrated the predictability of serum ferritin more than $500 \mathrm{ng} / \mathrm{mL}$ for 6 month and 1 year mortality with accuracy. ${ }^{12}$

In this study, we noted that the patients with higher ferritin values tend to have increased frequency of liver related clinical events. A ferritin value of $500 \mathrm{ng} / \mathrm{mL}$ had a sensitivity of $53.8 \%$ and specificity of $74.4 \%$ with the area under curve of 0.682 with $95 \%$ CI $(0.592-0.772)$ in our study. 
In the present study, we looked into the role of serum ferritin in predicting the 15-day mortality of patients admitted with cirrhosis liver and also the relation of serum ferritin to MELD score in chronic liver disease. We categorised the patients in 3 groups based on ferritin concentration, i.e. less than $200 \mathrm{ng} / \mathrm{mL}, 200$ to $400 \mathrm{ng} / \mathrm{mL}$ and more than $400 \mathrm{ng} / \mathrm{mL}$.

Many previous studies noticed no difference in age and gender among the three groups and this is important in Indian context, where the females are supposed to have comparatively lower body iron stores as compared to males of same age. But in our study, there was significant gender wise difference of ferritin distribution among the three ferritin groups.

Also we noted the inverse correlation of serum ferritin to serum haemoglobin. This may be due to its release secondary to internalisation of haemoglobin - haptoglobin complexes as a response to combat the oxidative stress by activated macrophages in these patients.

We noted a significant association of ferritin with serum creatinine including type 1 HRS. The significance of iron in acute kidney injury has also been validated recently following the introduction of N-GAL, which is an important iron transporting and iron-translocating compound. ${ }^{17}$

Our study based on the serum ferritin values in decompensated cirrhotic patients highlights the significance of ferritin as a prognostic biomarker. Also it provides more information on predictors of early mortality.

Patients with infection/ sepsis were not included in most of the previous studies, which looked into ferritin for the effect of sepsis on raised ferritin as acute phase reactant. But we included patients with infection/ sepsis also in our group, as bacterial infection or sepsis is an important early cause of death in these patients.

The emphasis on ferritin as a biomarker, which can be non-specifically elevated in multitude of conditions remains one of the major limitations of our study. Also the exclusion of patients with iron overload might have led to a potential selection bias in this study.

In summary, our results also clearly reflect the prognostic significance of increased serum ferritin values in patients with decompensated liver disease and cirrhosis at shortterm. However, further larger prospective studies with assessment of serum ferritin in all patents with cirrhosis irrespective of iron overload states are needed to validate these findings.

\section{CONCLUSION}

- Serum ferritin is a predictor of early mortality in patients with chronic liver disease.

- $\quad 41.2 \%$ of chronic liver disease patients had elevated serum ferritin, $2 \%$ had decreased serum ferritin and $56.8 \%$ had normal serum ferritin.

- Serum ferritin level has significant correlation to MELD score. As serum ferritin increases in chronic liver disease, MELD score also increases.

- Serum ferritin is elevated in various complications of chronic liver disease.

\section{REFERENCES}

[1] Dooley JS, Lok A, Burroughs AK, et al. Sherlock's Diseases of the liver and biliary system. $12^{\text {th }}$ edn. John Wiley \& Sons 2011: p. 790.
[2] Morrison ED, Brandhagen DJ, Phatak PD, et al. Serum ferritin level predicts advanced hepatic fibrosis among U.S. Patients with phenotypic hemochromatosis. Ann Intern Med 2003;138(8):627-33.

[3] Jacobs A, Worwood M. Ferritin in serum. Clinical and biochemical implications. $\mathrm{N}$ Engl J Med 1975;292(18):951-6.

[4] Kowdley KV, Belt P, Wilson LA, et al. Serum ferritin is an independent predictor of histologic severity and advanced fibrosis in patients with non-alcoholic fatty liver disease. Hepatology 2012;55(1):77-85.

[5] Kamath PS, Wiesner RH, Malinchoc M, et al. A model to predict survival in patients with end-stage liver disease. Hepatology 2001;33(2):464-70.

[6] Hiraoka A, Horiike N, Akbar SM, et al. Soluble CD 163 in patients with liver diseases: very high levels of soluble 163 in patients with fulminant hepatic failure. J Gastroenterol 2005;40(1):52-6.

[7] Moller HJ, Gronbaek H, Schiodt FV, et al. Soluble CD163 from activated macrophages predicts mortality in acute liver failure. J Hepatol 2007;47(5):671-6.

[8] Zelber-Sagi S, Nitzan-Kaluski D, Halpern Z, et al. NAFLD and hyperinsulinemia are major determinants of serum ferritin levels. J Hepatol 2007;46(4):700-7.

[9] Bugianesi E, Manzini P, D’Antico S, et al. Relative contribution of iron burden, HFE mutations and insulin resistance to fibrosis in non-alcoholic fatty liver. Hepatology 2004;39(1):179-87.

[10] Maiwall R, Kumar S, Chaudhary AK, et al. Serum ferritin predicts early mortality in patients with decompensated cirrhosis. Journal of Hepatology 2014;61(1):43-50.

[11] Pearlman FC, Lee RT. Detection and measurement of total bilirubin in serum, with use of surfactants as solubilizing agents. Clin Chem 1974;20(4):447-53.

[12] Walker NM, Stuart KA, Ryan RJ, et al. Serum ferritin concentration predicts mortality in patients awaiting liver transplantation. Hepatology 2010;51(5):1683-91.

[13] Attia KA, Ackoundou-N'guessan KC, N'-Yoman AT, et al. Child-Pugh-Turcott vs Meld score for predicting survival in a retrospective cohort Black African cirrhotic patients. World J Gastroenterol 2008;14(2):286-91.

[14] Halliday JW, Ramm GA, Powell LW, et al. Cellular iron processing and storage: the role of ferritin. In: Brock JH, Halliday JW, Pippard MJ, et al. eds. Iron metabolism in health and disease. London: WB Saunders 1994: p. 97-121.

[15] Wordwood M. Laboratory determination of iron status. In: Brock JH, Halliday JW, Pippard MJ, et al. eds. Iron metabolism in health and disease. London: WB Saunders 1994: p. 449-76.

[16] Searle SJ, Kerr KJR, Haliday JW, et al. Iron storage disease. In: MacSween RNM, Anthony PP, Scheuer PJ, et al. eds. Pathology of liver. Edinburgh: Churchill Livingstone 1994: p. 219-41.

[17] Kaushal GP, Shah SV. Challenges and advances in the treatment of AKI. J Am Soc Nephrol 2014;25(5):87783. 